This item was submitted to Loughborough's Research Repository by the author.

Items in Figshare are protected by copyright, with all rights reserved, unless otherwise indicated.

\title{
Analysis of electrical power data for condition monitoring of a small wind turbine
}

PLEASE CITE THE PUBLISHED VERSION

http://dx.doi.org/10.1049/iet-rpg.2012.0326

PUBLISHER

IET

VERSION

AM (Accepted Manuscript)

LICENCE

CC BY-NC-ND 4.0

REPOSITORY RECORD

Barton, John P., and Simon J. Watson. 2019. "Analysis of Electrical Power Data for Condition Monitoring of a Small Wind Turbine”. figshare. https://hdl.handle.net/2134/14421. 
This item was submitted to Loughborough's Institutional Repository (https://dspace.lboro.ac.uk/) by the author and is made available under the following Creative Commons Licence conditions.

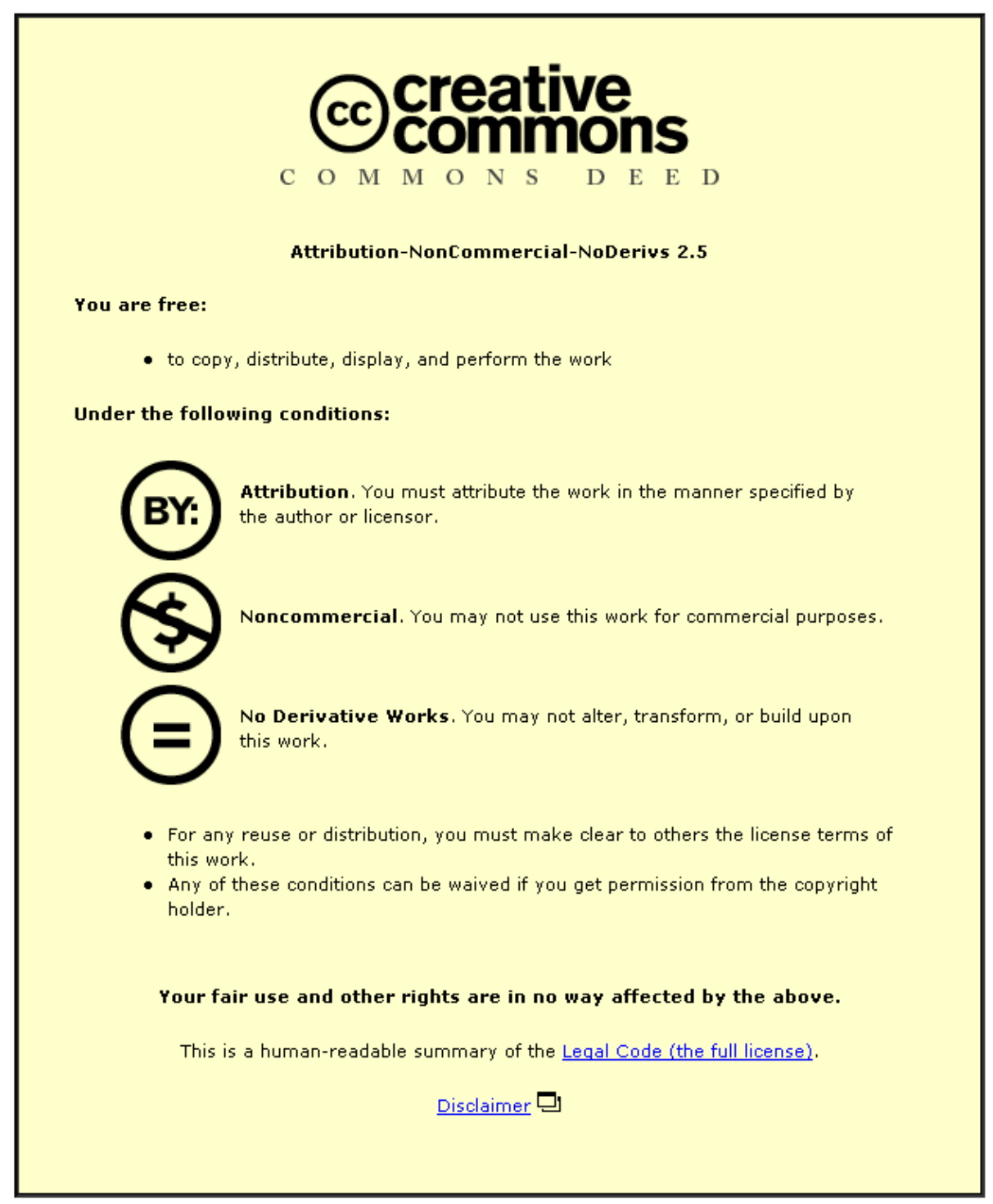

For the full text of this licence, please go to: http://creativecommons.org/licenses/by-nc-nd/2.5/ 


\title{
Analysis of Electrical Power Data for Condition Monitoring of a Small Wind Turbine
}

\author{
John P. Barton and Simon J. Watson \\ Centre for Renewable Energy Systems Technology, School of Electronic, Electrical and Systems \\ Engineering, Holywell Park, Loughborough University, LE11 3TU, UK \\ i.p.barton@lboro.ac.uk, s.j.watson@lboro.ac.uk
}

\begin{abstract}
Certain parts of a wind turbine, for example, the gearbox require significant time and heavy lifting equipment in the event of catastrophic failure necessitating replacement. Continuous condition monitoring has the potential to catch problems early, enable scheduled preventative maintenance and thereby reduce turbine downtime, reduce the number of site visits and prevent secondary damage. Accelerometers applied to mechanical components of the drive train are traditionally used for condition monitoring but require their own data acquisition system and analysis software. In contrast, the electrical current and voltage are continuously measured and could also be used for condition monitoring more cheaply.
\end{abstract}

An experimental data acquisition system has been installed on a small (25kW) onshore turbine in Leicestershire, UK to compare three-phase currents and voltages on the stator windings with six accelerometer signals. Data have been recorded before and after a gearbox failure and replacement. Data were analysed using both Fourier Transform and Morlet Continuous Wavelet Transform methods. Results show that the stator voltages show the same radial and axial mode vibration frequencies as the accelerometers and could therefore be used for condition monitoring. Furthermore, the stator currents show torsional modes of vibration not picked up by the accelerometers.

Keywords: Wind turbine, Condition monitoring, Data acquisition, Current, Voltage, Electrical Power

\section{Introduction}

Unplanned shutdowns reduce wind turbine availability and therefore energy yield. With the move to wind power offshore, such unplanned outages become even more costly due to restricted access. They often also result in costly deployment of equipment, for example. In the offshore environment, this includes ships and jack-up barges for maintenance. Certain parts of a turbine, for example, the gearbox require significant time and heavy lifting equipment in the event of subassembly replacement. Gearboxes have been reported as major source of failure in wind turbines $[1,2]$, though it is the associated downtime which is the main factor [3] and this is driving a better understanding of gearbox failure and the potential for timely preventative maintenance.

Continuous condition monitoring of wind turbines has the potential to catch problems early, enable an optimised condition based maintenance schedule and thereby reduce turbine downtime, reduce the number of call-outs and prevent secondary mechanical damage. The cost of an effective condition monitoring system (CMS) is justified even for a relatively modest increase in turbine availability [4]. A significant quantity of data can be generated by the wind turbine CMS and from the Supervisory Control And Data Acquisition (SCADA), the latter being standard in modern large scale wind turbines. The challenge is how to interpret the data and decide what is important. In addition, there is still significant progress that needs to be made to provide prognostic capability $[5,6]$. The use of SCADA data in a physics of failure approach to condition monitoring of wind turbine gearboxes has shown promise in detecting those gearboxes most likely to fail in a large fleet of turbines [7].

Accelerometers applied to mechanical components of the drive train are traditionally used for condition monitoring but require their own data acquisition system and analysis software [8]. In contrast, the electrical current and voltage are continuously measured and could also be used for condition monitoring. The main driver for using electrical signals is to reduce costs [9]. 
In many cases, wavelet analysis is preferable to frequency domain analysis. Usually, this is to extract fault signals at variable frequency from variable speed electrical generators [10-14], but also to perform modal analyses of mechanical systems excited by random forces [12], a situation similar to the research presented in this paper.

Monitored currents have been used to detect faults in wound rotor generators on test rigs [15, 16]. Monitoring of current and voltage have also been used to detect mechanical (bearing) problems on a generator test rig [17] and on the generator of a large wind turbine [18]. Moreover, gearbox tooth damage has been detected in a test rig by the Motor Current Signature Analysis (MCSA) of a motor driving a multistage gearbox [19-23] which was in turn driving a generator under a variable resistive load. Condition monitoring of mechanical parts of wind turbines using electrical signals has been previously attempted [24] but only to detect problems with rotor blades. To the authors' knowledge, this is the first time that high frequency $(4 \mathrm{kHz})$ monitoring of electrical signals has been used to detect drivetrain faults on a working wind turbine. In this paper, we look at the potential of monitoring generator electrical signals for detecting mechanical problems in a small wind turbine gearbox under real stochastic wind loading conditions.

\section{$2 \quad$ Wind Turbine}

An experimental data acquisition system has been installed on a small $(25 \mathrm{~kW})$ onshore wind turbine in Leicestershire, UK [25]. The wind turbine consists of a two-bladed rotor connected through a twostage gearbox, with a ratio of 1:12.748, to a four-pole squirrel cage induction generator. The nominal generator rotational frequency is 1500 revolutions per minute $(\mathrm{rpm})$ and the nominal turbine blade rotation frequency is $118 \mathrm{rpm}$. The entire power output of the turbine passes through two power electronic converters such that the generator frequency is independent of the grid to which it is connected. The grid-side converter is a Control Techniques 'Unidrive SP' [26] used as a DC-to-AC converter to export power and thereby maintain a constant voltage on the DC bus. The generator-side converter is a Control Techniques 'Unidrive Classic' [27] used as a AC-to-DC converter but this drive sets the power off-take of the turbine generator. The pulse-width-modulation (PWM) switching frequency of this second drive is $3 \mathrm{kHz}$ and appears to have impacted on the higher frequencies measured by the vibration sensors and electrical signals as described in Sections 3 and 4.

These power converters make possible a novel control system to optimise electricity generation in low and turbulent wind conditions, see Figure 1. At moderate to high wind speeds, and once stabilised, the turbine operates close to nominal speed and generates at $50 \mathrm{~Hz}$ electrical frequency; the generator voltage remains constant but currents are approximately proportional to instantaneous power output as seen in Region 2 of Figure 1. However, when the wind speed drops to close to or below cut-in wind speed, the turbine decelerates and generates below $50 \mathrm{~Hz}$ but continues to output 1 to $2 \mathrm{~kW}$ of power. This is an experimental system to enable the turbine to ride through wind calms between gusts, and to remain grid connected ready for the next gust of wind, thus capturing more wind energy in low wind speed conditions with turbulence. In low power, variable speed operation, the generator voltage remains constant and the currents are also approximately constant as shown in Regions 1,3 and 4 of Figure 1 . Note that the stator currents have been scaled using current transformers to be compatible with the data acquisition system. 


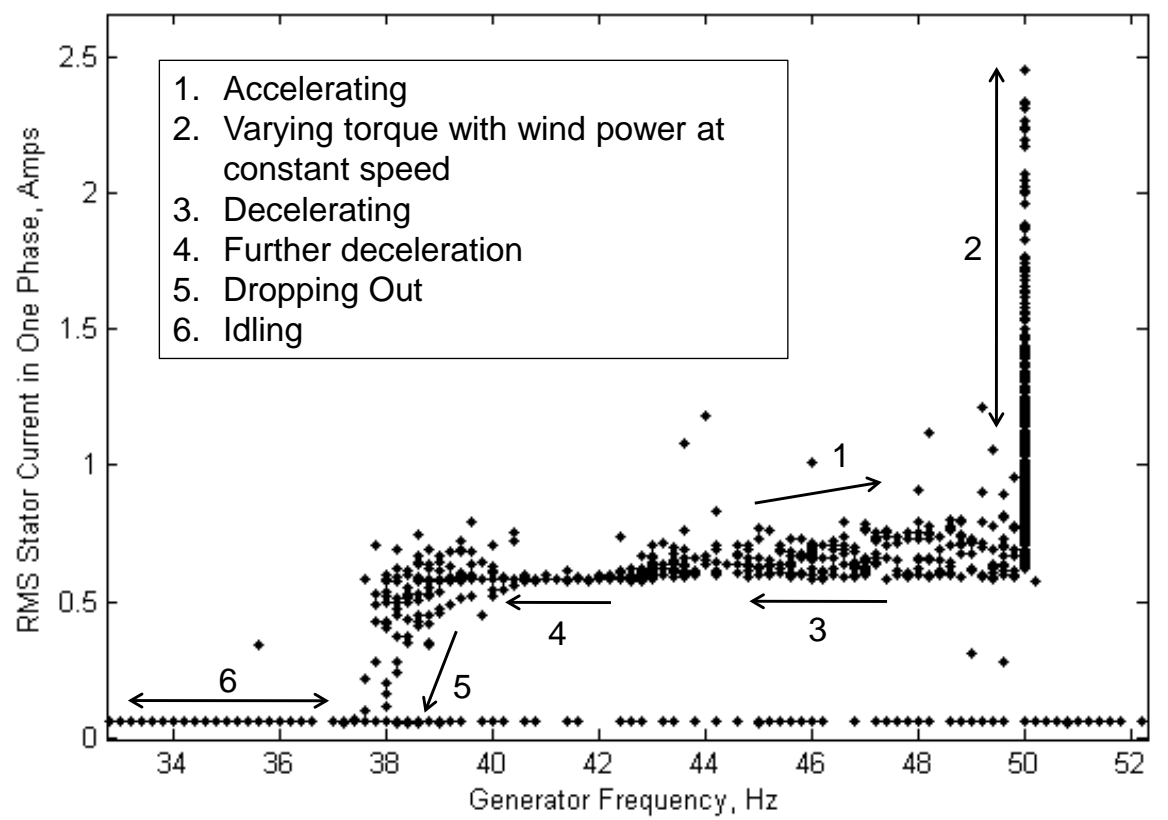

Figure 1: Stator current vs. electrical frequency illustrating the variable speed control system.

One advantage of the variable speed operation is that forced vibrations related to gearbox or bearing faults can be differentiated from natural frequencies, at least at low power conditions; in general, forcing frequencies change with the turbine rotation speed but natural frequencies remain constant.

Turbine rotational speed was not directly measured. The generator frequency was detected from the three-phase current signals; the current signals giving a much cleaner sine wave than the voltage signals. The generation frequency appears as the strongest component in a Fast Fourier Transform (FFT) spectrum of each current signal. Thus the electrical generation frequency was known but the turbine rotor rotational speed and the slip frequency could not be directly inferred. In this analysis, the generator slip was assumed to be small (typically less than 3\% for an induction machine) and generator frequency was therefore used as a proxy for high speed shaft rotation frequency from which blade rotor frequency was inferred, such that:

$$
\text { Rotation_Speed }(\mathrm{Hz})=N \times \text { Generation_Frequency } \times(1+s)
$$

Where: $N=$ Number of pole pairs ( 2 in this case)

$$
s=\text { Slip }
$$

It is also possible to directly estimate the rotation speed of the high speed shaft from a vibration analysis of the data. An FFT analysis of the current measurements, for example, yields a peak of vibration at half the generator frequency. However, the full speed frequency of the high speed shaft is only $25 \mathrm{~Hz}$ and therefore the high speed shaft completes only 125 rotations in each 5 -second sampling period. The shaft frequency can be calculated to an accuracy of only $+/-0.2 \mathrm{~Hz}$ at best. The uncertainly in the rotation speed is therefore $+/-1 \%$ and is similar in magnitude to the slip.

Higher frequencies corresponding to phenomena such as rotor bar passing frequency are unusable as speed measurements because they are indistinguishable from harmonics of the generator frequency.

\section{Data Acquisition}

High-speed $(4 \mathrm{kHz})$ data acquisition consisted of six accelerometers attached to the gearbox, plus three line-to-line voltage transducers and three current transducers on the three-phase output of the generator, as shown in Figure 2. A description of each of the transducers is given in Table 1. The signals from the transducers are sent to a data acquisition card connected to a PC. 


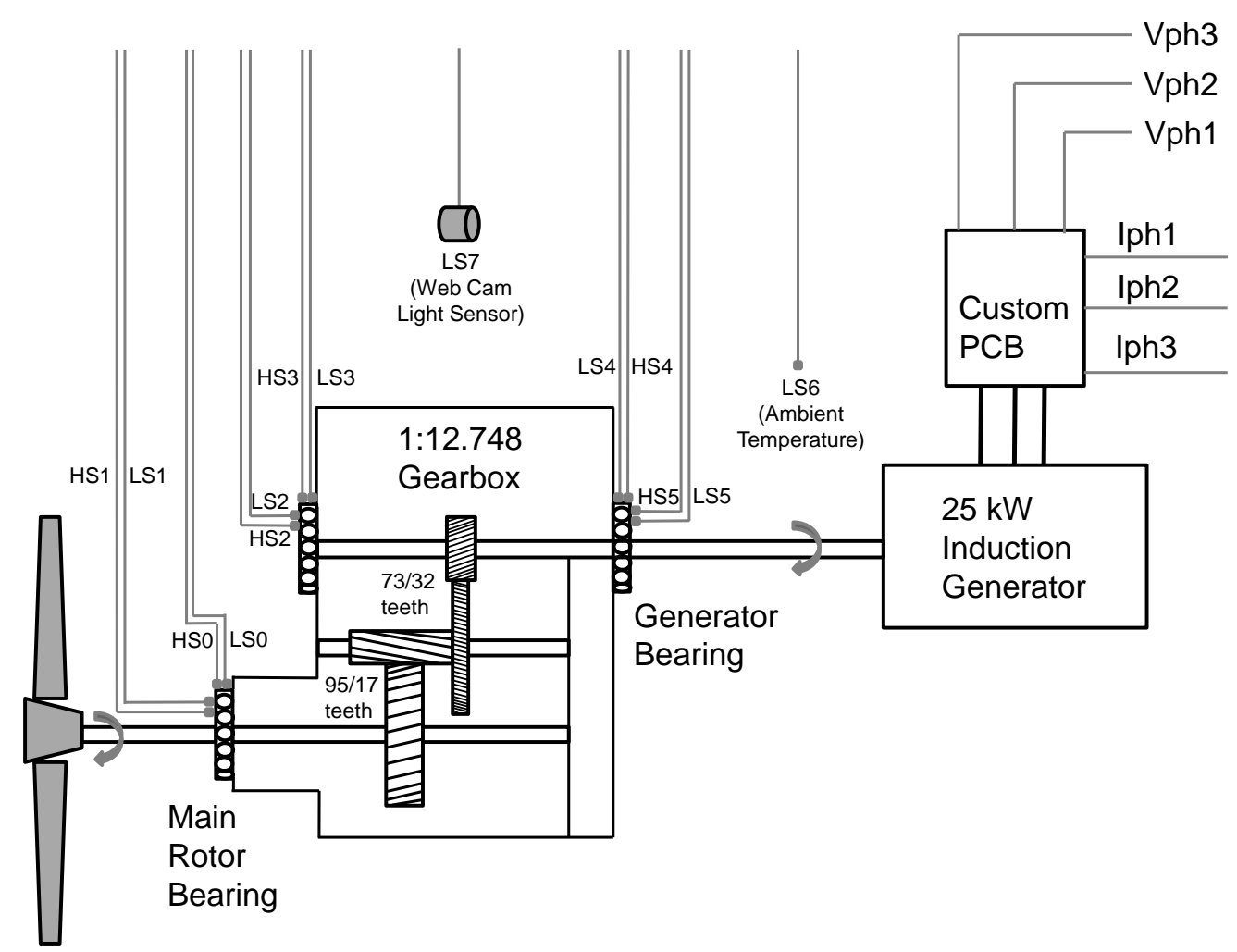

Figure 2: Location of the transducers.

Table 1: Description of the transducers.

\begin{tabular}{|l|l|l|l|}
\hline $\begin{array}{l}\text { Sensor } \\
\text { Name }\end{array}$ & Location & Type & $\begin{array}{l}\text { Sampling } \\
\text { Frequency }\end{array}$ \\
\hline HS0 & Side of gearbox casing, near main low speed bearing & $\begin{array}{l}\text { Piezoelectric } \\
\text { Accelerometer }\end{array}$ & $4 \mathrm{kHz}$ \\
\hline HS1 & End of gearbox casing, near main low speed bearing & $\begin{array}{l}\text { Piezoelectric } \\
\text { Accelerometer }\end{array}$ & $4 \mathrm{kHz}$ \\
\hline HS2 & End of gearbox casing, high speed shaft end bearing & $\begin{array}{l}\text { Piezoelectric } \\
\text { Accelerometer }\end{array}$ & $4 \mathrm{kHz}$ \\
\hline HS3 & Side of gearbox casing, high speed shaft end bearing & $\begin{array}{l}\text { Piezoelectric } \\
\text { Accelerometer }\end{array}$ & $4 \mathrm{kHz}$ \\
\hline HS4 & Side of gearbox casing, near generator shaft bearing & $\begin{array}{l}\text { Piezoelectric } \\
\text { Accelerometer }\end{array}$ & $4 \mathrm{kHz}$ \\
\hline HS5 & End of gearbox casing, near generator shaft bearing & $\begin{array}{l}\text { Piezoelectric } \\
\text { Accelerometer }\end{array}$ & $4 \mathrm{kHz}$ \\
\hline Vph1 & Phase 1 line from wind turbine generator & Voltage Sensor & $4 \mathrm{kHz}$ \\
\hline Vph2 & Phase 2 line from wind turbine generator & Voltage Sensor & $4 \mathrm{kHz}$ \\
\hline Vph3 & Phase 3 line from wind turbine generator & Voltage Sensor & $4 \mathrm{kHz}$ \\
\hline Iph1 & Phase 1 line from wind turbine generator & Current Sensor & $4 \mathrm{kHz}$ \\
\hline Iph2 & Phase 2 line from wind turbine generator & Current Sensor & $4 \mathrm{kHz}$ \\
\hline Iph3 & Phase 3 line from wind turbine generator & Current Sensor & $4 \mathrm{kHz}$ \\
\hline LS0 & Side of gearbox casing, near main low speed bearing & Thermocouple & $1 \mathrm{kHz}$ \\
\hline LS1 & End of gearbox casing, near main low speed bearing & Thermocouple & $1 \mathrm{kHz}$ \\
\hline LS2 & End of gearbox casing, high speed shaft end bearing & Thermocouple & $1 \mathrm{kHz}$ \\
\hline LS3 & Side of gearbox casing, high speed shaft end bearing & Thermocouple & $1 \mathrm{kHz}$ \\
\hline LS4 & Side of gearbox casing, near generator shaft bearing & Thermocouple & $1 \mathrm{kHz}$ \\
\hline LS5 & End of gearbox casing, near generator shaft bearing & Thermocouple & $1 \mathrm{kHz}$ \\
\hline LS6 & Inside nacelle, near but not in contact with gearbox & Thermocouple & $1 \mathrm{kHz}$ \\
\hline LS7 & Inside nacelle, looking through grill towards blades & Web Camera & $1 \mathrm{kHz}$ \\
\hline & & & \\
\hline
\end{tabular}


This paper describes the analysis of the high-speed data sampled at $4 \mathrm{kHz}$. All transducers were working correctly except for Iph2. A reference temperature measurement was made inside the nacelle and a light level transducer used to detect day and night and to predict solar temperature gain. The analysis of the low speed, $1 \mathrm{kHz}$ sampled data is not described in this paper.

Data were recorded over the two weeks leading up to a gearbox failure and replacement in June 2010. These data were compared with a period from April to June 2011 after gearbox replacement when it was assumed that no gearbox fault was developing. Indeed, no gearbox failures occurred previously in 2011 or since during 2012.

The high speed data were recorded in bursts of five seconds separated by at least 50 minutes. Sometimes the gaps between each five-second burst of data were longer than 50 minutes, especially when wind speeds were low and the turbine was not generating continuously. A recording period of five seconds was short enough that the turbine rotation frequency did not change significantly during the period.

Each five-second period was long enough to resolve a relatively wide range of frequencies. The lowest measurable frequency was $0.2 \mathrm{~Hz}$, the frequency with a period of five seconds. The highest measurable frequency was $2 \mathrm{kHz}$, i.e. the Nyquist frequency of the sampling rate of $4 \mathrm{kHz}$. However, there was no anti-aliasing on the input signals, so all frequencies higher than $2 \mathrm{kHz}$ appear at lower frequencies. In particular, the switching frequency of the generator-side PWM power converters is known to be $3 \mathrm{kHz}$. Oscillations of the PWM converters appear as a clear spike in the FFT spectrum at $1 \mathrm{kHz}$. According to the technical manual, harmonics are also expected at multiples of this frequency and at sidebands of these frequencies separated by $+/$ - the generator frequency [27].

Ideally anti-aliasing filters would have been used in the experiment, but it was thought that only lower frequencies would be of interest. With aliasing, harmonics and sidebands of the switching frequency are expected at frequencies given by:

Where:

$$
f=n P W M f+m G e n f+p f s
$$

$P W M f=$ PWM switching frequency $=3000 \mathrm{~Hz}$

Genf = generator frequency, 37 to $50 \mathrm{~Hz}$

$f s=$ sampling frequency $=4000 \mathrm{~Hz}$

$n, m, p$ are integers, the most importance of which are $n=-1, m=-6$ to +6 and $p=+1$.

Looking at the data and significant vibration frequencies it may be that the external line frequency (constant $50 \mathrm{~Hz}$ ) is also important since strong vibrations and electrical oscillations are observed at constant frequencies, independent of wind turbine rotation speed, between $650 \mathrm{~Hz}$ and $2000 \mathrm{~Hz}$.

\section{$4 \quad$ Method}

The high-speed $(4 \mathrm{kHz})$ data were analysed using both FFT and Morlet Continuous Wavelet Transform (CWT) methods. The data were first analysed using an FFT only but it became apparent that almost all detected frequencies were constant natural frequencies that did not change with turbine rotational speed. These frequencies must be driven by impulses of noise or intermittent forcing vibrations but it was difficult to see where the impulses were coming from. Where these impulses are cyclic, they should appear as amplitude modulations of the natural frequencies and hence a CWT was also used. Since the PWM frequency appears in the spectrum at $1 \mathrm{kHz}$, with considerable sideband activity, all frequencies above $600 \mathrm{~Hz}$ were excluded from the CWT analysis to avoid the alias of the PWM converter and its sidebands. There still remained $47 \mathrm{CWT}$ frequency bands between $0.2 \mathrm{~Hz}$ and $600 \mathrm{~Hz}$ and to see the effect on all these frequencies, each one was put through an FFT to calculate their amplitude modulation, followed by an averaging over all bands. Since the meaningful modulation frequencies must be lower than the frequencies they apply to, the output of the CWT analysis only extends to $500 \mathrm{~Hz}$. The FFT of the CWT between $500 \mathrm{~Hz}$ and $600 \mathrm{~Hz}$ was omitted firstly because there were very little data in this band and secondly because it is meaningless to say that the amplitude of a $600 \mathrm{~Hz}$ signal varies at $500 \mathrm{~Hz}$. 
The steps in the two methods (FFT and CWT) were:

\section{Fast Fourier Transform (FFT) Method}

1. Perform FFT of time series data in each data channel.

2. Group spectrum into 400 bins each separated by $2.3 \%$.

3. Pick out resonant frequencies.

Notes:

- FFT frequency bins were chosen at geometric intervals, each bin boundary being 1.023293 times ( $=10$ to the power of 0.01 ) larger than the previous one.

- This frequency interval gave a smooth spectrum but clearly showed the frequency spikes.

- It was not so small that variable rotation-speed-linked frequencies moved from one bin to another during each 5-second measurement period.

- It was small enough that resonant frequencies could be distinguished from one another and appeared as sharp spikes.

\section{Continuous Wavelet Transform (CWT) Method}

1. Perform CWT of data in 54 frequency bands.

2. Perform FFT of data in each CWT band ( 400 frequency bins, separated by $2.3 \%$ as in the FFT Route).

3. From FFT, select key frequency bands and reanalyse CWT output.

4. Average the spectra amplitudes across all CWT bands excluding high frequencies.

5. Produce a single spectrum of 400 frequency bins for each event.

6. Pick out resonant and forcing frequencies.

Notes:

- The CWT frequency bands were chosen to give both good time resolution and frequency resolution.

- The CWT yields amplitude of each frequency that changes within the 5-second period, but this is very difficult to interpret. This amplitude is therefore put through an FFT analysis to find forcing frequencies. As above, the FFT frequency bins were chosen at geometric intervals, each separated from the previous one by a factor of 1.023293 .

\section{$5 \quad$ Results and Discussion}

\section{$5.1 \quad$ FFT Spectra}

All channels of data showed good results except one of the current signals (Iph2) that was clearly reading lower values than the other current signals.

Results showed that the electrical data could indeed indicate the same principal vibration frequencies as the accelerometers and could therefore potentially be used for condition monitoring. Figure 3 and Figure 4 show the low frequency end of the FFT spectrum of accelerometer and voltage data respectively produced by analysing two five-second events when the generator frequency was $50 \mathrm{~Hz}$. The first event in 2010 was recorded before the gearbox change and the second after the gearbox change due to failure. Although, there are differences in the apparent frequencies seen between the 2010 and 2011 events, which will be discussed in Section 5.6, the similarity between the accelerometer-derived and voltage sensor-derived FFT spectra can clearly be seen. 


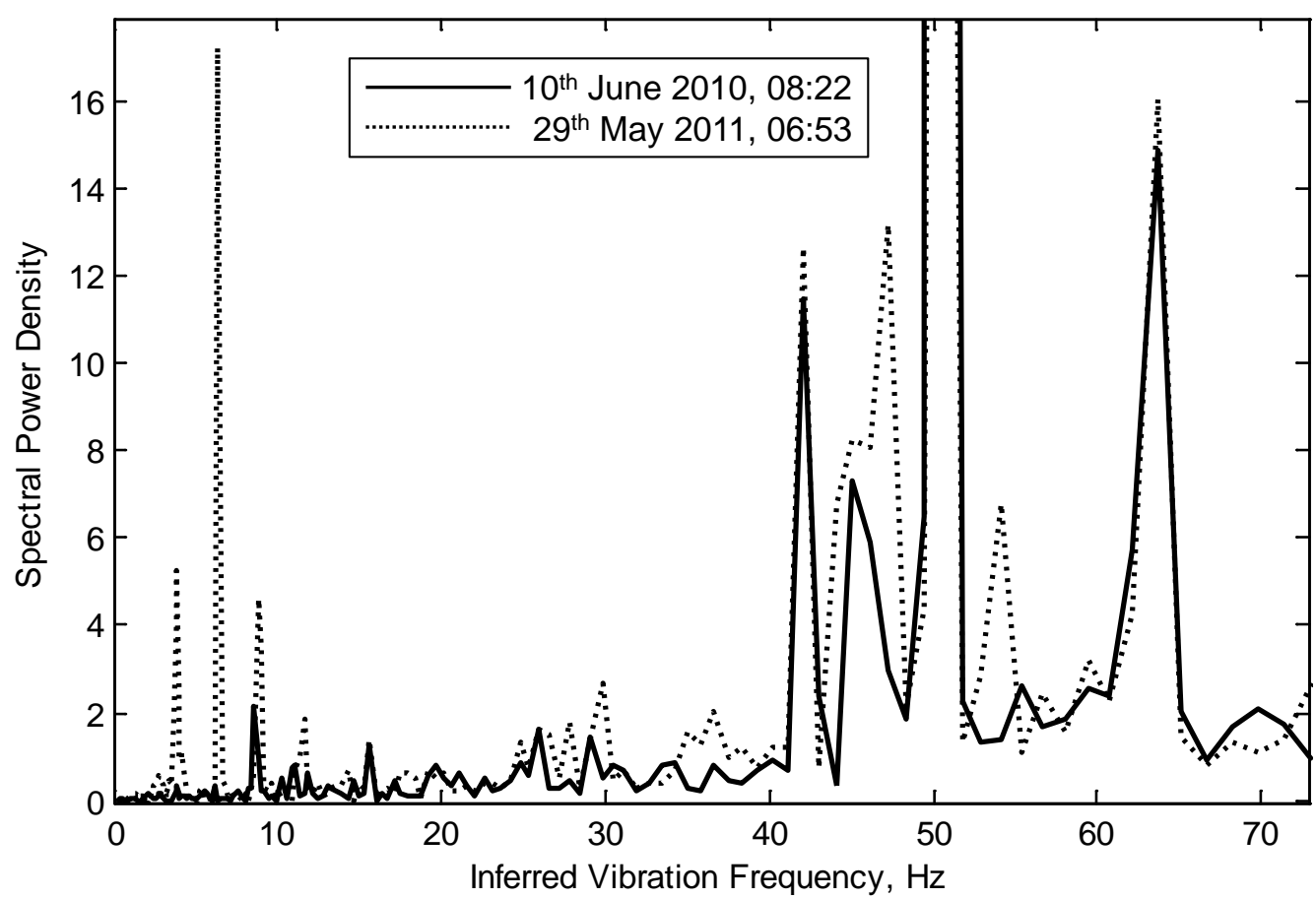

Figure 3: Low frequency FFT of accelerometer HS5 five-second data at 08:22 on $10^{\text {th }}$ June 2010 (before gearbox failure) compared with 06:53 on $29^{\text {th }}$ May 2011 (after replacement).

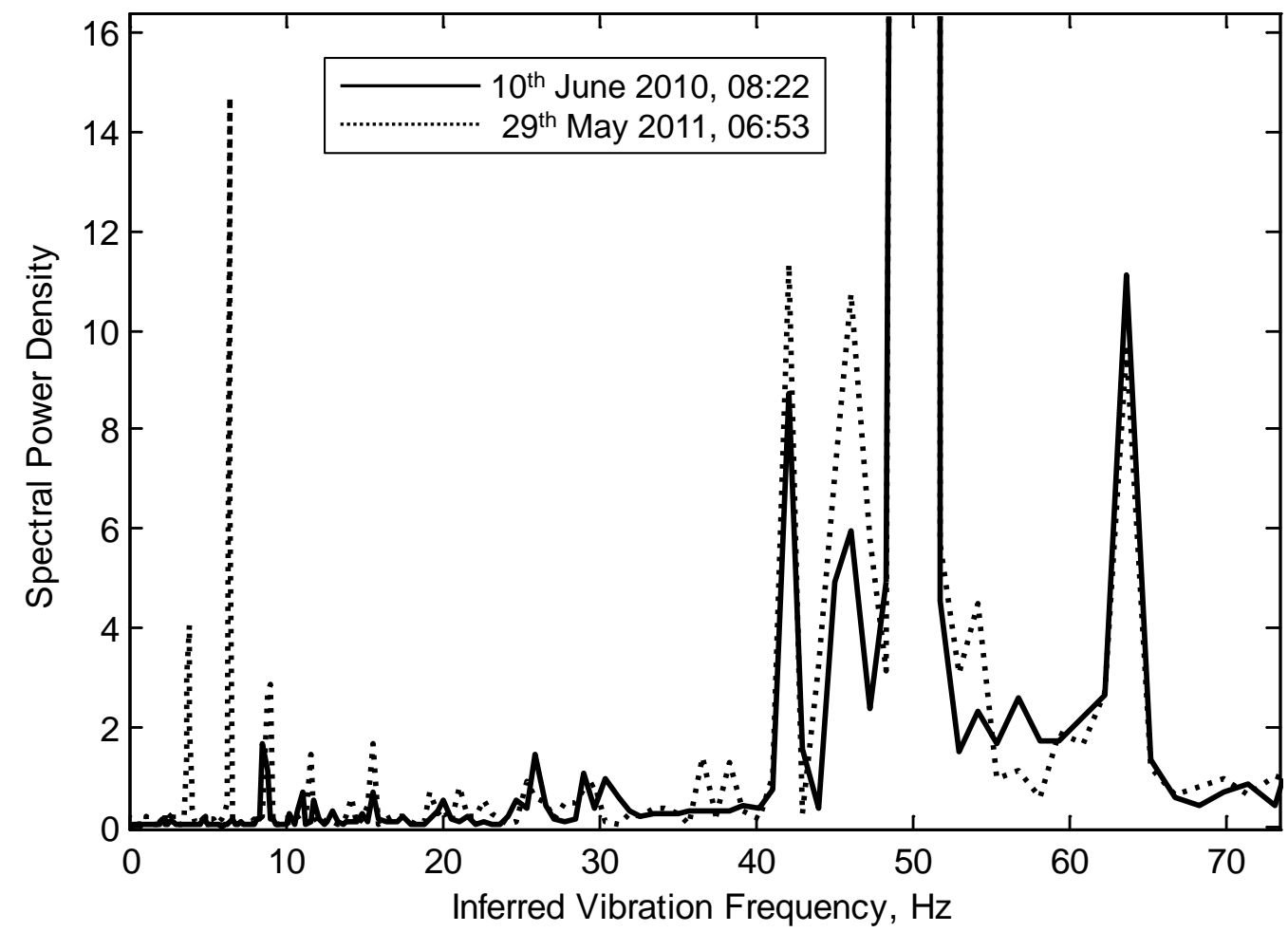

Figure 4: Low frequency FFT of voltage sensor (Vph1) five-second data at 08:22 on $10^{\text {th }}$ June 2010 (before gearbox failure) compared with 06:53 on $29^{\text {th }}$ May 2011 (after replacement). 
The different types of sensor have different frequency weightings: since high frequency vibrations produce large accelerations for a given displacement, higher frequencies show up strongly in the accelerometers even when lower frequency vibrations have larger amplitudes of displacement. The voltage sensors pick up the generator frequency very strongly but also pick up many of the same vibration frequencies as the accelerometers, with high frequencies detected more strongly than low ones. Using basic electromagnetic theory, the voltage induced in the stator windings is proportional to the rate of change of flux in the stator windings [28]:

$$
e=B L u
$$

Where:

$e=$ induced stator voltage

$B=$ magnetic flux density

$L=$ length of conductor

$u=$ local velocity of relative motion

The flux linkage with the rotor is inversely proportional to the air gap [29]:

Where:

$$
B=\frac{m m f \cdot \mu}{\delta}
$$

$m m f$ = magnetic motive force

$\mu=$ permeability of air

$\delta=$ air gap

If the net electrical load on the generator is mainly inductive, then high frequency vibrations will appear mainly as changes in stator voltage rather than stator current.

The current sensors also detect vibration frequencies but at much lower amplitudes than the generator frequency. The current signals consist almost entirely of the fundamental generation frequency but with other frequencies and harmonics of the generation frequency added on at amplitudes that are several orders of magnitude lower. Nevertheless, the signal-to-noise ratio of these frequencies, as seen in Figure 5, was good enough to consistently detect some vibration frequencies. The overall difference in amplitude between 2010 and 2011 is not significant, being due to an instantaneous difference in output power between the two measurement periods. 


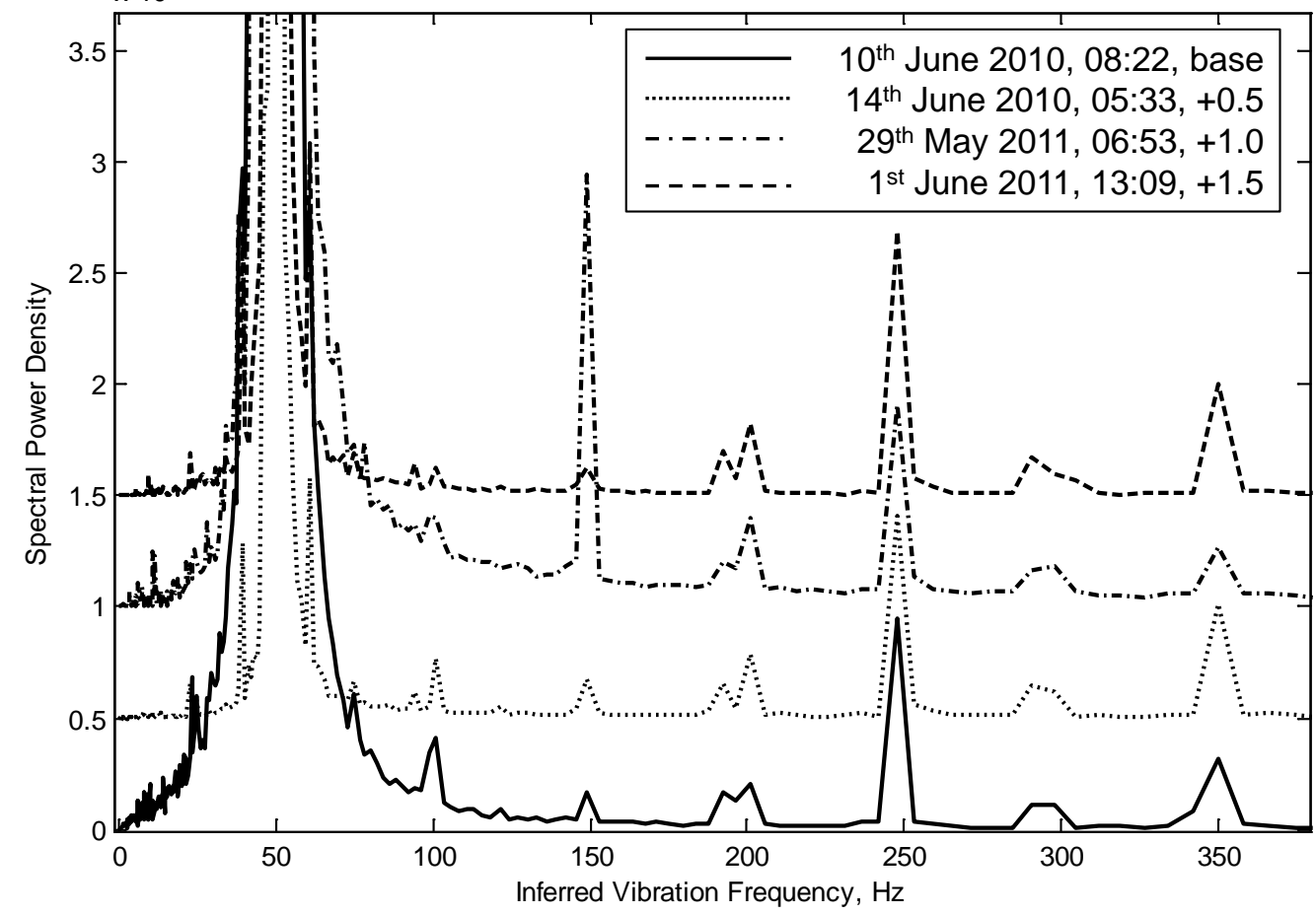

Figure 5: Low frequency FFT of a current sensor (Iph1) five-second data at 08:22 on $10^{\text {th }}$ June 2010 and at 05:33 on 14 $4^{\text {th }}$ June 2010 (before gearbox failure) compared with 06:53 on $29^{\text {th }}$ May 2011 and at 13:09 on $1^{\text {st }}$ June 2011 (after replacement). An offset has been added to each line to separate data for clarity as indicated in the legend.

Figure 5 shows that some of the frequencies detected by the current sensors are the same as the accelerometers and voltage sensors (e.g. $6.4 \mathrm{~Hz}$ and $11.6 \mathrm{~Hz}$ ) but most are different.

Interestingly, one high speed data acquisition channel was left unused but still picked up frequencies of the generator, the shaft frequencies and harmonics of the generator frequency. Some of its FFT frequencies were the same as the current transducers and others were not. It is therefore probable that some of the current sensor vibrations were picked up by electromagnetic inductance, indicating noisy data. Nevertheless, given the physical separation of all the sensors from the PWM power converters or any other electrical equipment, it is hard to see how these oscillations can be anything other than genuine vibration modes of the turbine rotor, generator and gearbox feeding through as electrical signals.

\subsection{FFT Variation with Generator Frequency}

Most frequencies detected by both the accelerometers and the electrical signals were constant natural frequencies, invariant with electrical generation frequency as shown in the FFT spectra from accelerometer HS3 in Figure 6. In this plot, FFT spectra of many five-second bursts of data are plotted side-by-side as contour plots and arranged in order of generator frequency which is related to the rotor speed. The rotor is thus exciting the turbine structure across a frequency range and the figure is showing the FFT response at each of the frequencies in this range. Each rotation frequency is assumed to be fixed for each five-second burst. The $\mathrm{x}$-axis is generation frequency in $\mathrm{Hz}$ which is proportional to rotation frequency assuming a small slip frequency. The $y$-axis is vibration frequency on a logarithmic scale (log base 10 of cycles per second).

The dark grey and black shades indicate high vibration levels while the light and white areas indicate no or low vibration levels. The horizontal dark bands show that many vibration modes are invariant with generator frequency. 


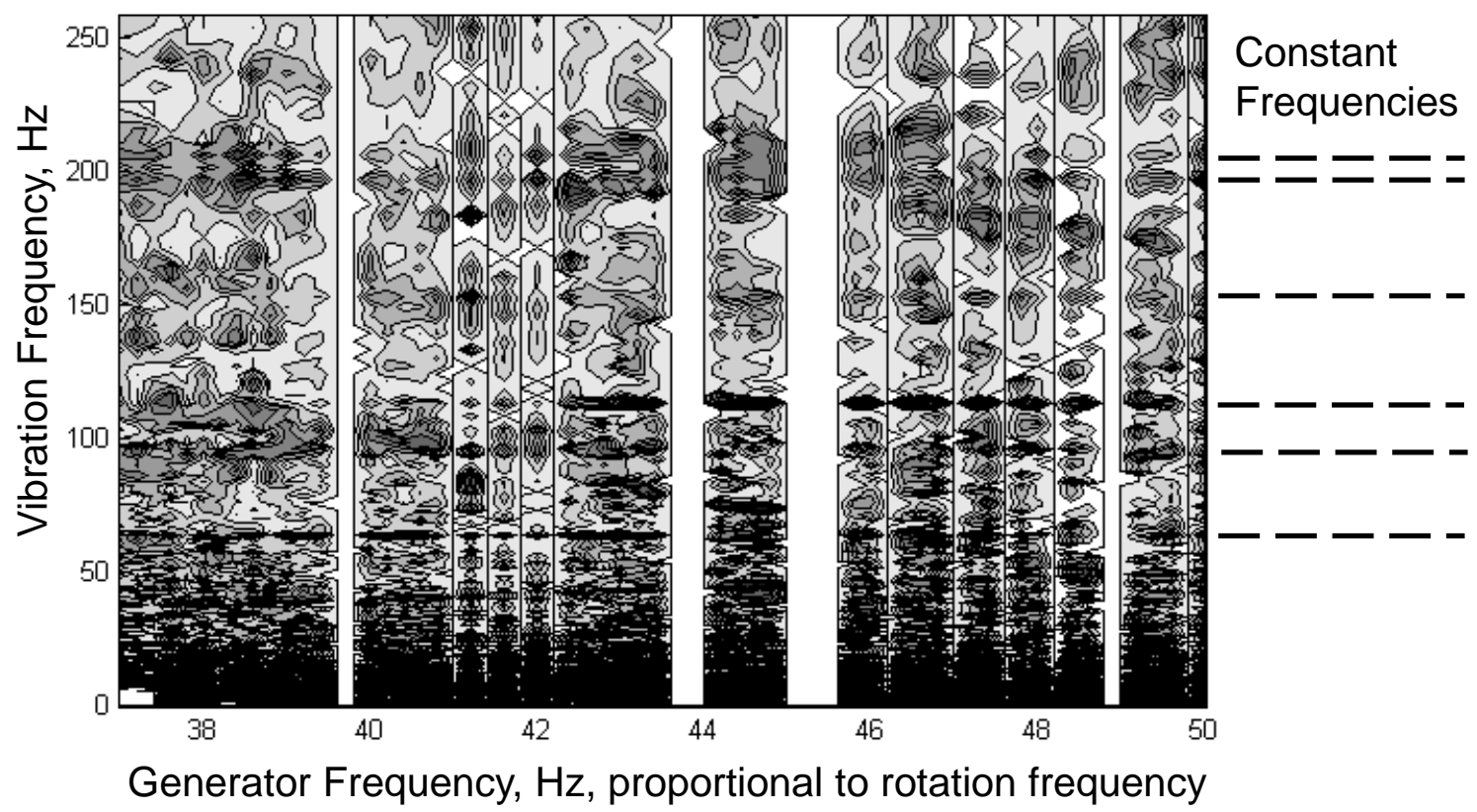

Figure 6: FFT Contour plot of vibration level vs. generator frequency and vibration frequency in June 2010 (before gearbox failure) measured using accelerometer HS3 and focussing on higher frequencies.

\subsection{CWT Variation with Generator Frequency}

The results of the CWTs of accelerometer and voltage sensor data show fewer constant frequencies but still fail to show many forcing frequencies that are proportional to rotational speed, as can be seen in Figure 7 for accelerometer HS3. In fact, both FFT and CWT analyses show some frequencies that fall as the generator frequency rises. It is thought that these are related to an interaction of the stator magnetic field with the squirrel cage rotor bars or the axial tie bars, and are the subject of on-going investigation.

Although the actual number of rotor bars is not known, a typical design of induction generator of $25 \mathrm{~kW}$ (30 to $40 \mathrm{HP}$ ) has 48 stator slots and 40 rotor bars [30]. At $50 \mathrm{~Hz}$ generation frequency, this would result in a nominal rotor bar passing frequency of $1000 \mathrm{~Hz}$ which coincides with the alias of the PWM switching frequency and is therefore very difficult to spot. On the other hand, there are 12 obvious axial tie bars running through the rotor that would produce a nominal passing frequency of $300 \mathrm{~Hz}=$ $12 \times$ high speed shaft frequency. These may or may not be the working rotor bars of the induction generator, but it is observed that most of the odd, changing frequencies have gradients equal to $+/-12$ $\mathrm{x}$ the high speed shaft frequency. 


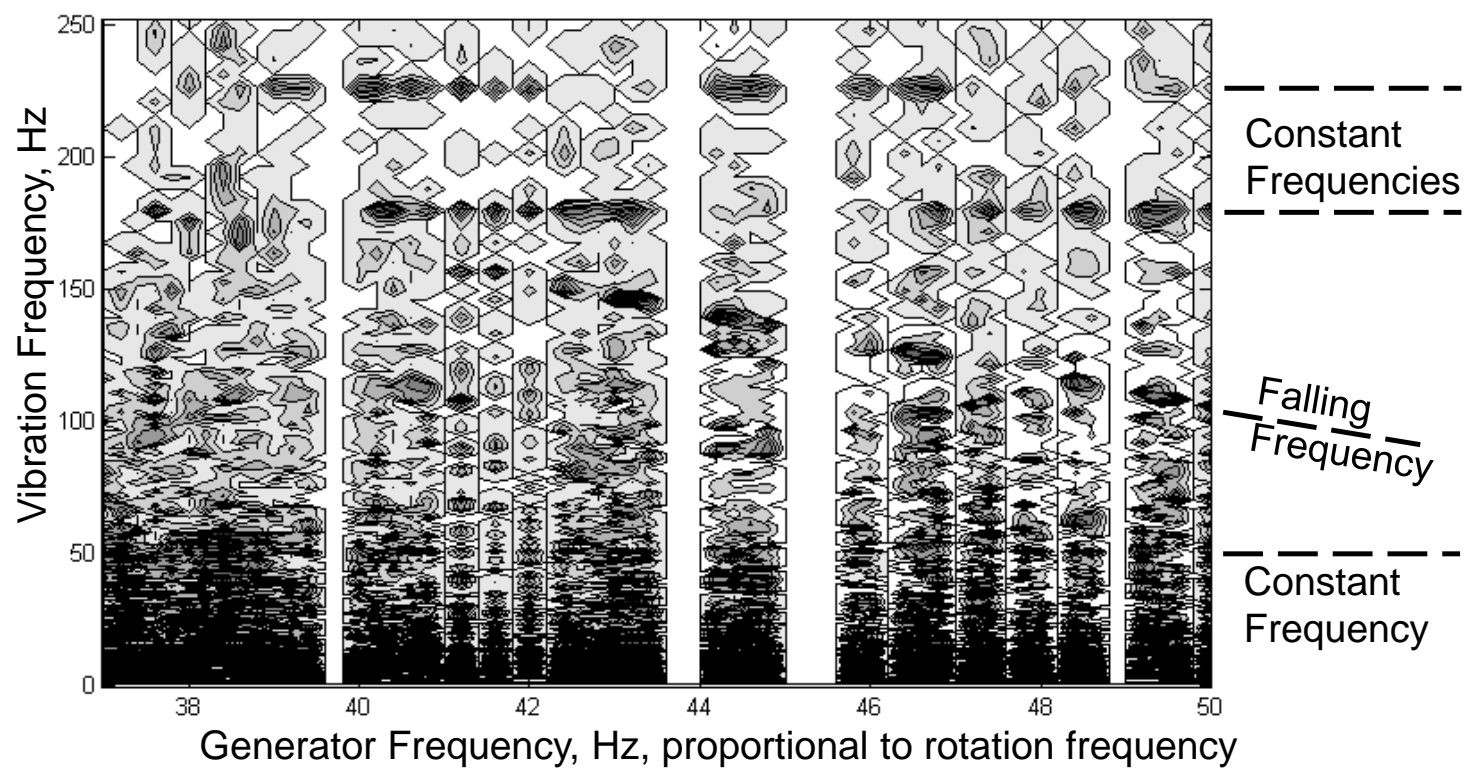

Figure 7: CWT contour plot of vibration level vs. generator frequency and vibration frequency in June 2010 (before gearbox failure) measured using accelerometer HS3 and focussing on higher frequencies.

For most results, the voltage sensors are almost equivalent to the accelerometer results but the current sensors measure different frequencies. In fact, the current sensors are much better at picking up vibration frequencies of the blades, shaft rotational speeds and generator harmonics. Figure 8 shows the CWTs of current sensor Iph1 in 2010. The key frequencies picked up by the analysis are shown as dotted lines.

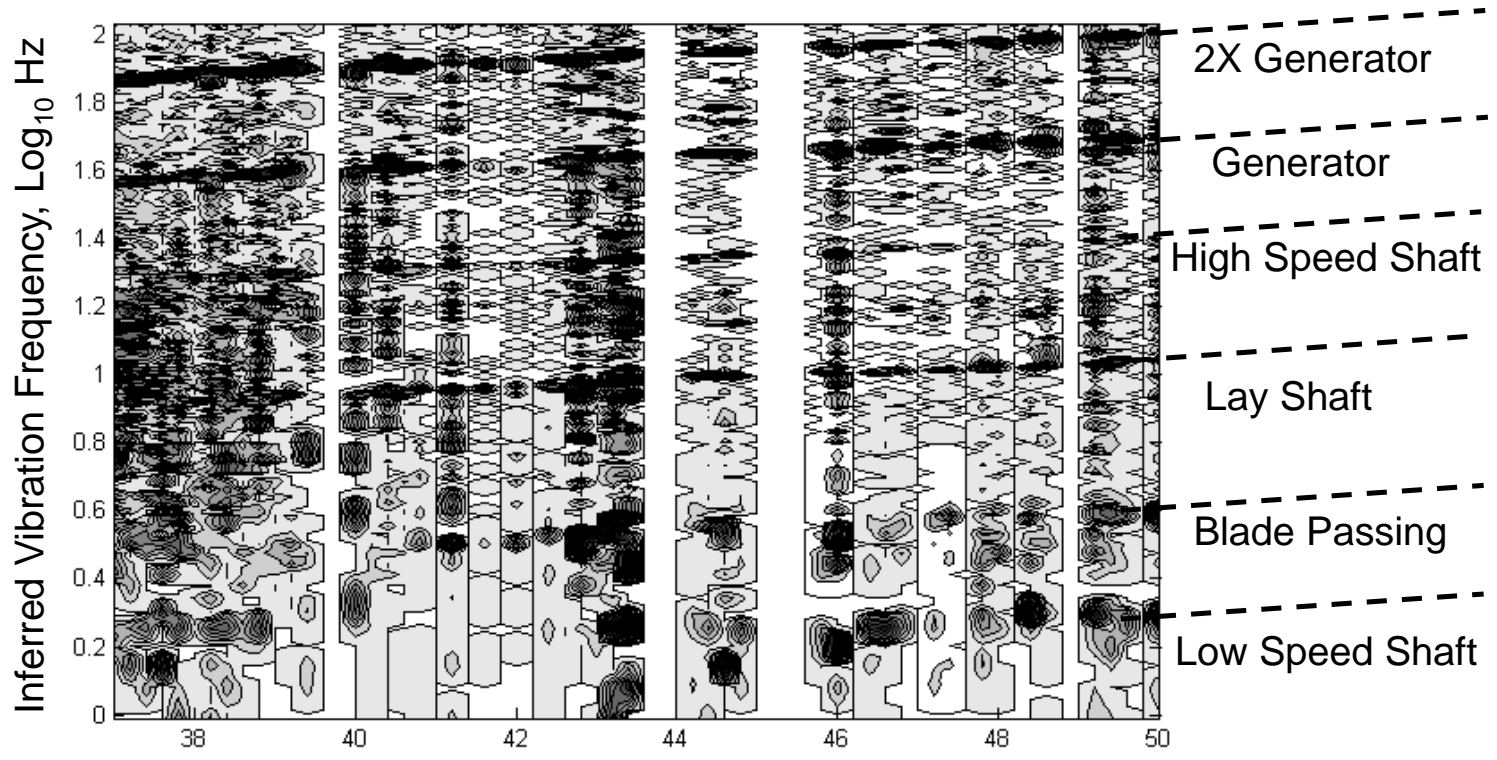

Generator Frequency, $\mathrm{Hz}$, proportional to rotation frequency

Figure 8: CWT contour plot of vibration level vs. generator frequency and vibration frequency in June 2010 (before gearbox failure) measured using current sensor Iph1 and focussing on lower frequencies. 


\subsection{FFT and CWT Analysis of Current Measurements}

One possible reason for the greater sensitivity of current sensors to shaft rotation frequencies is that the current sensors pick up torsional vibration whereas the accelerometers and voltage sensors pick up axial and lateral vibrations. Changes in rotation speed cause a change in rate of cutting of magnetic flux, hence change in current, whereas axial and lateral vibrations cause changes in the size of the air gap in the generator, causing changes in voltage. More evidence for this is provided by the CWT analysis of the generator frequency. A simple time trace of the current measurements show them to be an almost smooth sine wave at the generator frequency. All other frequencies are several orders of magnitude smaller.

A CWT analysis was performed on the current sensor data when the turbine was running at full speed and one wavelet frequency band was selected, that centred on $50.9 \mathrm{~Hz}$, which was closest to the generator frequency of $50 \mathrm{~Hz}$. As expected, this was the band with the greatest average amplitude. The variation in amplitude of this single frequency component was a measure of the magnitude of the AC current. This was a measure of the turbine torque and therefore power output at constant rotational speed. Significant variation can be seen in Figure 9 over the whole five-second period.

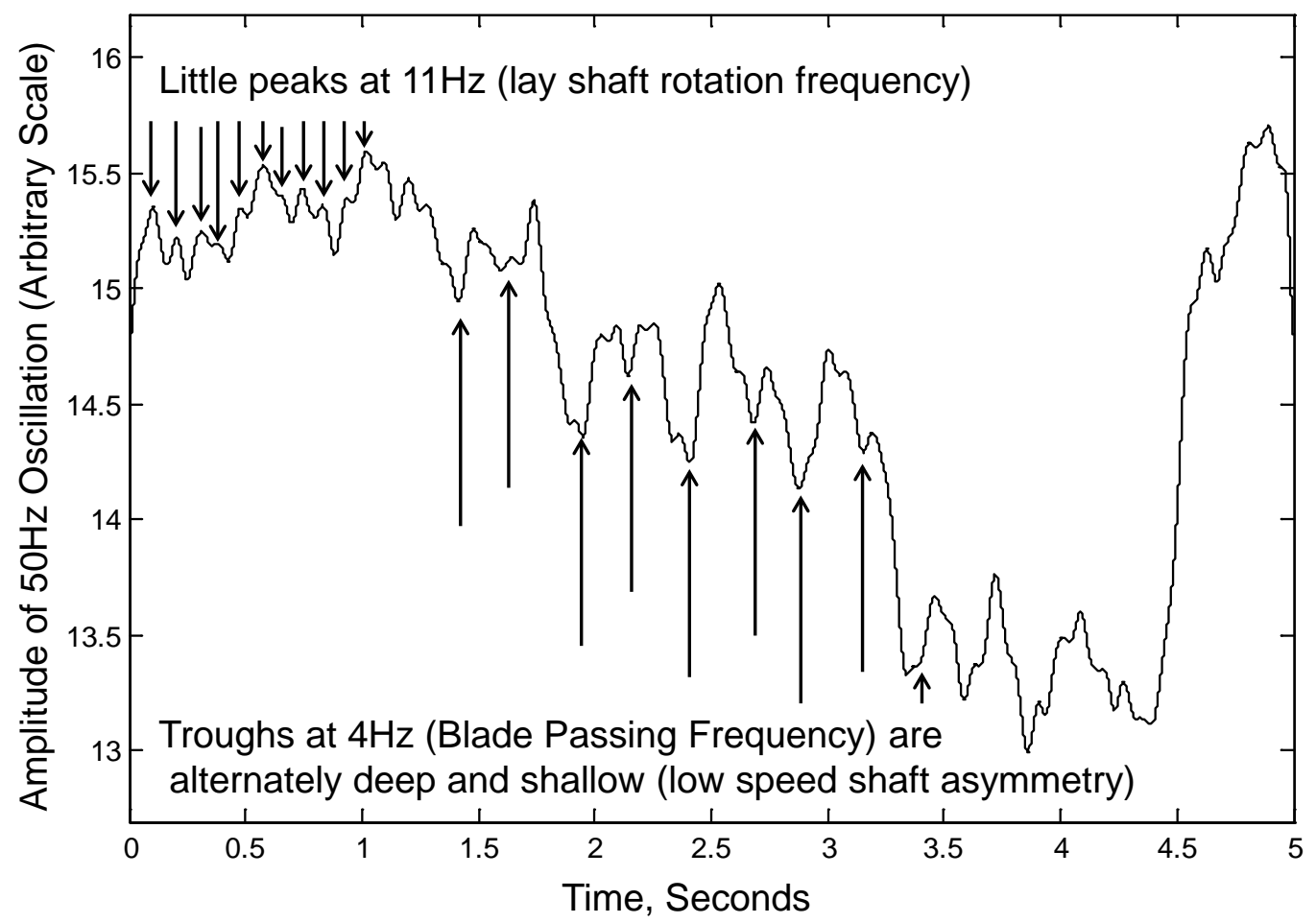

Figure 9: CWT of the $50 \mathrm{~Hz}$ frequency of current sensor Iph1 at 13:37 on $14^{\text {th }}$ June 2010 (before gearbox failure).

Over this period, the current and therefore power output rises to a peak, slowly falls and then rises to another peak, due to turbulent variation in wind speed, but shorter term variations can also be seen in Figure 9. The small oscillations at about $11 \mathrm{~Hz}$ are due to asymmetry in the intermediate or 'lay' shaft gear wheels. The larger oscillations at $4 \mathrm{~Hz}$ are due to the blade passing through the wake of the tower. These troughs in current are seen to be alternately deep and shallow, presumably due to asymmetry in the low speed shaft and differences between the two blades.

When FFT analysis is performed on many data events with different rotation frequencies, it is possible to see not only the generator frequency and its harmonics and the high speed shaft frequency (50\% of generator frequency) but also some sidebands on the generator frequency at $78 \%$ and $122 \%$ of generator frequency, as seen in Figure 10. The same sidebands were seen in data from 2010 and 2011. 


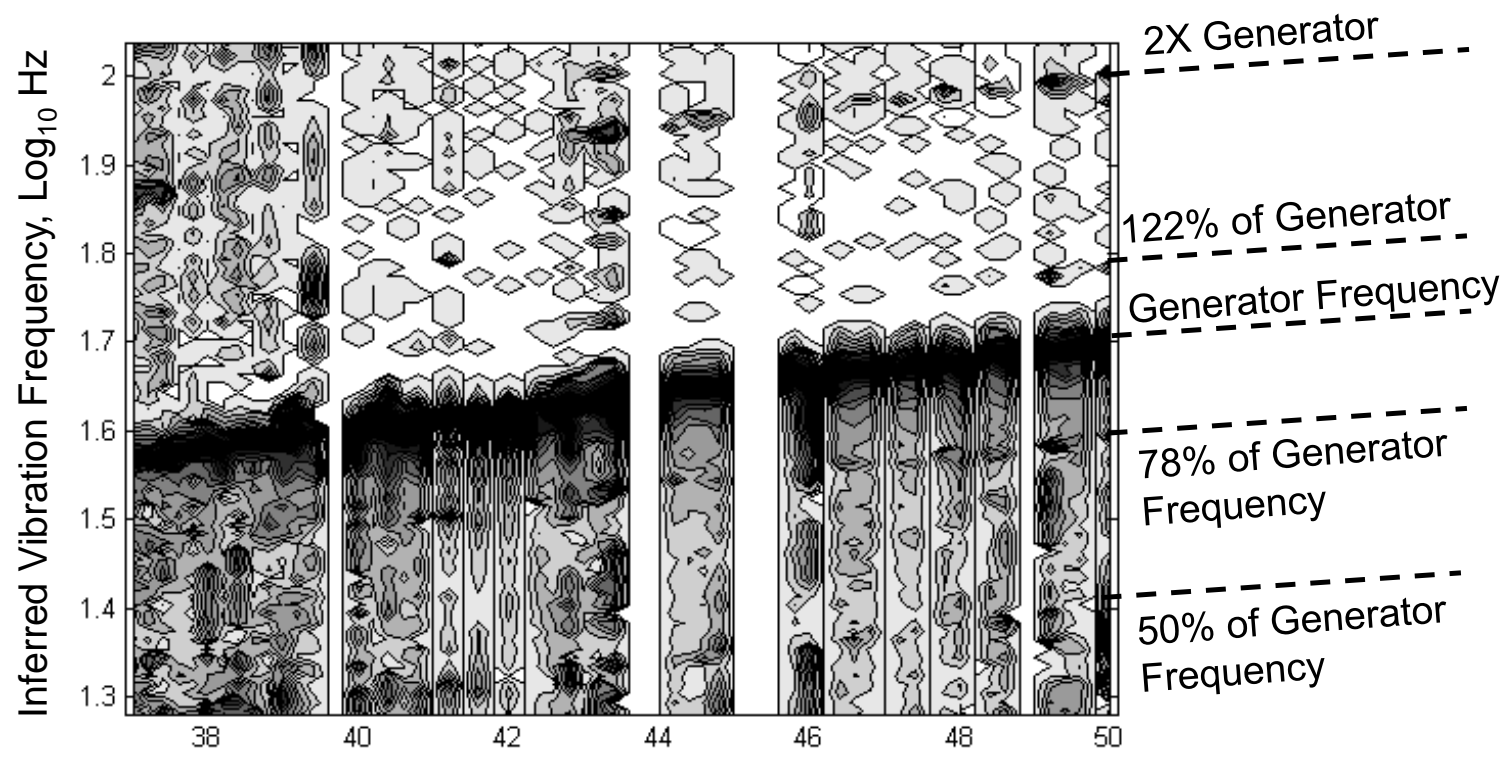

Generator Frequency, $\mathrm{Hz}$, proportional to rotation frequency

Figure 10: FFT analysis of current sensor Iph3 taken from data in June 2010 (before gearbox failure) at variable rotation speeds.

In contrast to the CWT analysis shown in Figure 7 , the lay shaft frequency (22\% of generator frequency) is not visible in the FFT analysis shown in Figure 10. This is further evidence for the modulation of the generator frequency at the lay shaft frequency namely: if the generator frequency were denoted $A$ and the lay shaft frequency $B$, then the modulation of $A$ at frequency $B$ gives rise to side bands at frequencies $(A-B)$ and $(A+B)$ :

$$
2 \cos A \cos B=\cos (A-B)+\cos (A+B)
$$

Therefore sidebands are expected at generator frequency $+/$ - lay shaft frequency: $50 \mathrm{~Hz}+/-11 \mathrm{~Hz}=$ $39 \mathrm{~Hz}$ and $61 \mathrm{~Hz}$, as observed.

\subsection{Increased Vibration Level Associated with Gearbox Failure}

The ratio of vibration amplitudes before compared to after the gearbox replacement was calculated to highlight those vibrations that were larger in the failing gearbox. One significant difference found was in the amplitudes of vibration at $196 \mathrm{~Hz}$ and $206 \mathrm{~Hz}$ detected by all six accelerometers and all three voltage sensors. The levels of these vibrations increased significantly three days before gearbox failure, as seen in Figure 11. Note that the amplitude of vibration is not related to overall turbine power level since the data events chosen for analysis were all in a narrow band of power (and current). Figure 11 also shows the high degree of correlation between all the accelerometers and between accelerometers and voltage sensors. Each point on the $\mathrm{x}$-axis of this graph represents a different data event.

Note that the current sensors did not measure this vibration mode. The amplitude at these frequencies as measured by the current sensors did not correlate with the accelerometers or with the voltage sensors. In addition, the current sensors did not show any marked increase in amplitude at $196 \mathrm{~Hz}$ or $206 \mathrm{~Hz}$ with impending gearbox failure. 


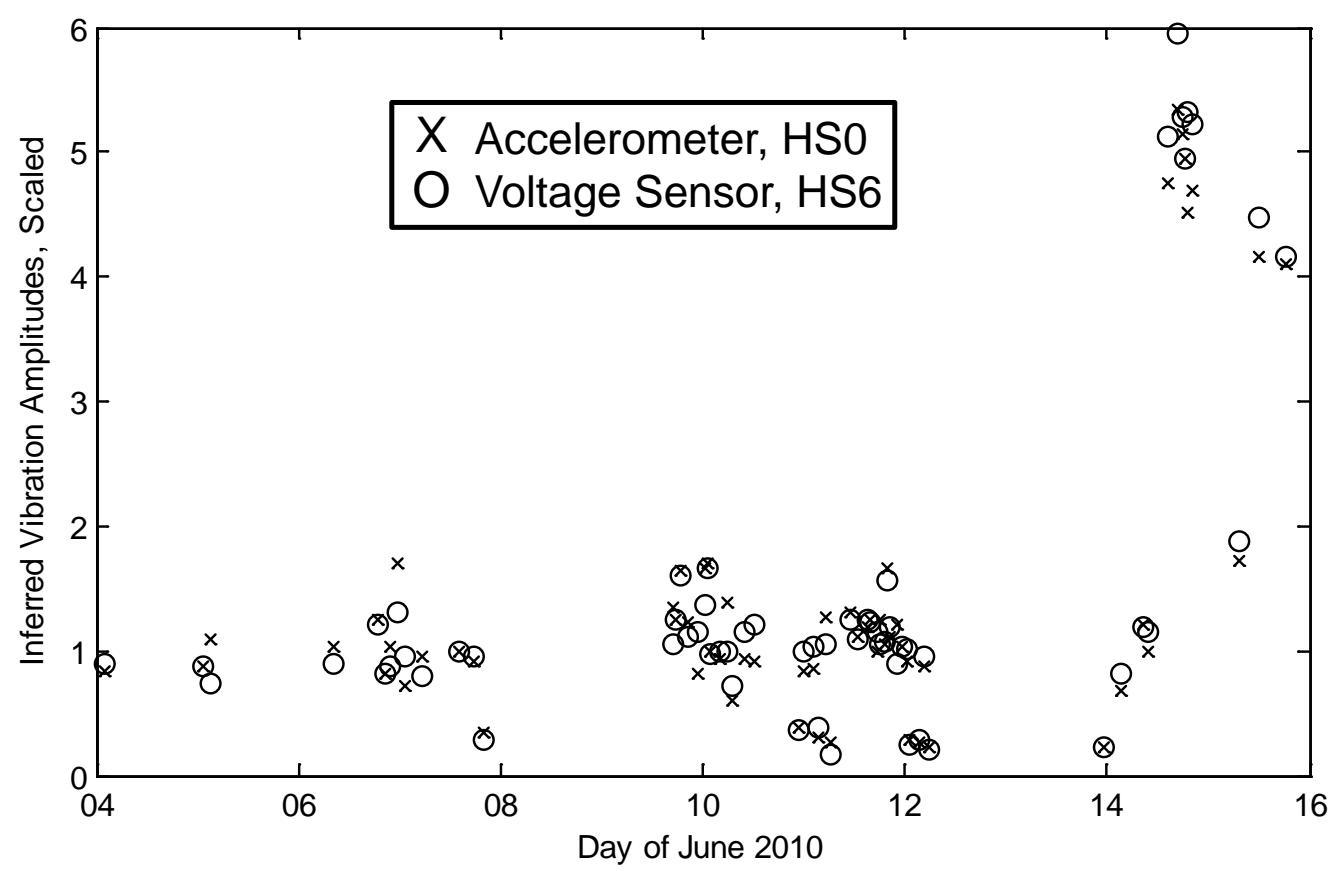

Figure 11: Amplitude of vibrations at $196 \mathrm{~Hz}$ and $206 \mathrm{~Hz}$ (averaged together) in events in June 2010 (leading up to gearbox failure) measured using accelerometer HSO and voltage sensor Vph1, both calculated by FFT analysis.

The proximity of the $196 \mathrm{~Hz}$ and $206 \mathrm{~Hz}$ vibrations to the low speed gear meshing frequency $(186 \mathrm{~Hz})$ is significant, indicating damaged gear teeth. Records of the damage to this failed gearbox were not available but a previous gearbox failure of these turbines did include the stripping of the 17 teeth on the low speed meshing end of the lay shaft as shown in Figure 12.

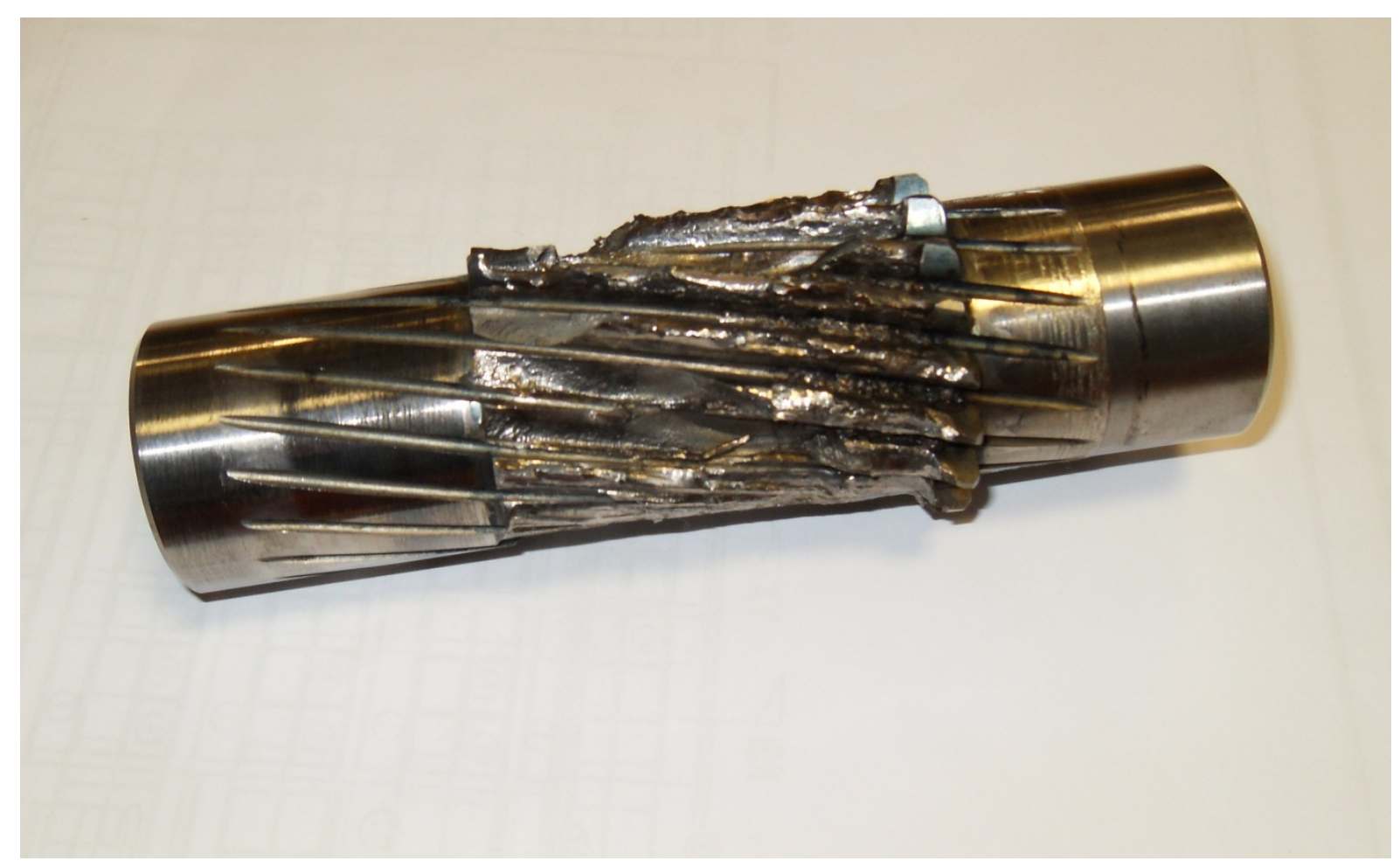

Figure 12: Photograph of stripped low speed gear teeth on lay shaft of a previously failed gearbox. 
The fact that the observed frequencies of vibration did not occur exactly at the tooth meshing frequency but above it by $10 \mathrm{~Hz}$ and $20 \mathrm{~Hz}$ respectively suggests that they are side band frequencies. The interval of $10 \mathrm{~Hz}$ is very close to the lay shaft nominal rotational frequency of $11 \mathrm{~Hz}$. This is exactly as expected from a worn or broken gear tooth or set of adjacent gear teeth: they would produce increased vibration at the tooth meshing frequency but modulated at the shaft rotation frequency. As explained in Section 5.4 above, the Fourier spectrum will exhibit sidebands separated from the main frequency by the rotation frequency, in this case the lay shaft frequency. This is consistent with the results from a gearbox test rig [31], except that in the case of that test rig, the sideband frequencies were observed either side of a harmonic of the meshing frequency, not the meshing frequency itself. Other researchers also claim the detection of gearbox faults through sidebands and harmonics of meshing frequencies $[14,32]$.

\subsection{Low Frequency Vibrations}

Looking back at Figure 3 and Figure 4, some unexplained frequencies are very evident at $2.8 \mathrm{~Hz}$, $3.8 \mathrm{~Hz}$ and $6.4 \mathrm{~Hz}$ in 2011 that are not visible in 2010. A smaller peak was also visible in 2011 at about $1.2 \mathrm{~Hz}$. Both accelerometer and voltage sensors show this difference. These oscillations do not change in frequency with generator frequency and have not been physically identified. They are unlikely to be due to a failing gearbox since the amplitudes are much higher after gearbox replacement. Since the frequencies are so low, they are more likely due to vibrations of the guyed wind turbine tower and guy wires. Some unknown change appears to have occurred between 2010 and 2011. It is possible that the tensions of the guy wires have changed, for example.

\section{Conclusions}

This paper has presented the results of an analysis of vibration and electrical signals measured on the drive train of a small $25 \mathrm{~kW}$ wind turbine.

The current sensors are more suited to measuring torsional vibrations, e.g. the characteristic vibration frequencies of the drive train shafts and the blade passing frequency. Most frequencies measured by the current sensors are proportional to the rotor speed.

The voltage sensors are shown to be more sensitive to translation and axial vibrations because they pick up the same frequencies as measured by the accelerometers attached to the outside of the gearbox.

The amplitude of data at particular key frequencies as measured by all three voltage sensors showed an increase in magnitude in advance of gearbox failure, as did those of all the accelerometers. These frequencies are consistent with being sidebands of a tooth meshing frequency caused by damage to teeth on the lay shaft. Stripping of teeth was shown to be the source of failure in a previous identical gearbox as used in this wind turbine. Clearly, further work and more examples of gearbox failure are required to show definitively that these vibrations are directly related to this proposed failure mode.

It has been shown for the first time, therefore, that high speed sampling of the electrical power output of a working wind turbine can be used to infer modes of vibration in the drive train, including the gearbox, and could be used for low cost drive train mechanical fault monitoring, though significant work remains to be done to make an operational condition monitoring system based on this principle.

\section{Acknowledgements}

The authors would like to thank Prof. Tony Marmont of Beacon Energy Limited for allowing access to the $25 \mathrm{~kW}$ wind turbine and to the EPSRC for funding this work through the Supergen Wind consortium grants, EP/D034566/1 and EP/H018662/1.

\section{References}

[1] Ribrant, J. and Bertling, L.M.: 'Survey of failures in wind power systems with focus on Swedish wind power plant during 1997-2005', IEEE Transactions on Energy Conversion, 2007, 22, (1), pp. 167-173. 
[2] Tavner, P.J., Xiang, J. and Spinato, F.: 'Reliability analysis for wind turbines', Wind Energy, 2007, 10, pp. 1-18.

[3] Spinato, F., Tavner, P.J., Van Bussel, G.J.W. and Koutoulakos, E.: 'Reliability of wind turbine subassemblies', IET Renewable Power Generation, 2008, 3, (4), pp. 387-401.

[4] Nilsson, J. and Bertling, L.: 'Maintenance management of wind power systems using condition monitoring systems-life cycle cost analysis for two case studies', IEEE Transactions on Energy Conversion, 2007, 22, (1), pp. 223-229.

[5] Wiggelinkhuizen, E., Verbruggen, T., Braam, H., Rademakers, L., Xiang, J. and Watson, S.: 'Assessment of condition monitoring techniques for offshore wind farms', Journal of Solar Energy Engineering - Transactions of the ASME, 2008, 130, pp. 031004-1 - 031004-9.

[6] Hameed, Z., Ahn, S.H. and Cho, Y.M.: 'Practical aspects of a condition monitoring system for a wind turbine with emphasis on its design, system architecture, testing and installation', Renewable Energy, 2010, 35, pp. 879-894.

[7] Gray, C.S. and Watson, S. J.: 'Physics of failure approach to wind turbine condition based maintenance', Wind Energy, 2010, 13, pp. 395-405.

[8] Hameed, Z., Hong, Y.S., Cho, Y.M., Ahn, S.H. and Song, C.K.: 'Condition monitoring and fault detection of wind turbines and related algorithms: A review', Renewable and Sustainable Energy Reviews, 2009, 13, (1), pp. 1-39.

[9] Daneshi-Far, Z., Capolino, G.A., Henao, H.: 'Review of failures and condition monitoring in wind turbine generators', Proceedings of the XIX International Conference on Electrical Machines, Kuala Lumpur, Malaysia, 29 November $-1^{\text {st }}$ December 2010, pp. 1-6.

[10] Shaohua, L., Dongxiang, J., Minghao, Z.: 'Experimental investigation and analysis for gearbox fault', World Non-Grid-Connected Wind Power and Energy Conference, Nanjing, China, 5-7 November 2010, pp. 1-6.

[11] Vilchis-Rodriguez, D.S., Djurovic, S., Smith, A. C. and Crabtree, C. J.: 'Wind turbine induction generator fault frequency tracking by reference frame transformation', Proceedings of the 6th IET International Conference on Power Electronics, Machines and Drives, Bristol, UK, 27-29 March 2012, pp. 1-6.

[12] Gouttebroze, S. and Lardies, J.: 'On using the wavelet transform in modal analysis', Mechanics Research Communications, 2001, 28, (5), pp. 561-569.

[13] Bin, L., Yaoyu, Y., Xin, W. and Zhongzhou, Y.: 'A review of recent advances in wind turbine condition monitoring and fault diagnosis', IEEE Conference on Power Electronics and Machines in Wind Applications, Milwaukee, WI, USA, 24-26 June 2009, pp. 1-7.

[14] García Márquez, F.P., Tobias, A.M., Pinar, Pérez, J.M. and Papaelias, M.: 'Condition monitoring of wind turbines: Techniques and methods'. Renewable Energy, 2012, 46, pp. 169-178.

[15] Crabtree, C.J., Djurović. S., Tavner, P.J. and Smith, A.C.: 'Fault frequency tracking during transient operation of wind turbine generators', Proceedings of the XIX International Conference on Electrical Machines, Kuala Lumpur, Malaysia, 29 November $-1^{\text {st }}$ December 2010, pp. 1-5.

[16] Djurović, S., Crabtree, C.J., Tavner, P.J., and Smith A.C.: 'Condition monitoring of wind turbine induction generators with rotor electrical asymmetry', IET Renewable Power Generation, 2012, 6, (4), pp. 207-216. 
[17] Yang, W., Tavner, P.J., Crabtree, C.J. and Wilkinson, M.: 'Cost-effective condition monitoring for wind turbines', IEEE Transactions on Industrial Electronics, 2010, 57, (1), pp. 263-271.

[18] Watson, S.J., Xiang, B.J., Yang, W.X., Tavner, P.J. \& Crabtree, C.J.: 'Condition monitoring of the power output of wind turbine generators using wavelets', IEEE Transactions on Energy Conversion, 2010, 25, (3), pp. 715-721.

[19] Kar, C. and Mohanty, A.R.: 'Monitoring gear vibrations through motor current signature analysis and wavelet transform', Mechanical Systems and Signal Processing, 2006, 20, pp. 158-187.

[20] Mohanty, A.R. and Kar, C.: 'Fault detection in a multistage gearbox by demodulation of motor current waveform', IEEE Transactions on Industrial Electronics, 2006, 53, (4), pp. 1285-1297.

[21] Kar, C. and Mohanty, A.R.: 'Multistage gearbox condition monitoring using motor current signature analysis and Kolmogorov-Smirnov test', Journal of Sound and Vibration, 2006, 290, pp. 337-368.

[22] Kar, C. and Mohanty, A.R.: 'Technical note: gearbox health monitoring through multiresolution Fourier transform of vibration and current signals', Structural Health Monitoring, 2006, 5, pp. 195-200.

[23] Kar, C. and Mohanty, A.R.: 'Vibration and current transient monitoring for gearbox fault detection using multiresolution Fourier transform', Journal of Sound and Vibration, 2008, 311, pp. 109-132.

[24] Jeffries W. Q., Chambers J. A., Infield D. G.: 'Experience with bicoherence of electrical power for condition monitoring of wind turbine blades', IEE Proceedings - Vision, Image, and Signal Processing, 1998, 145, pp.141-148.

[25] Beacon Energy Ltd, http://www.beaconenergy.co.uk/, accessed 10 ${ }^{\text {th }}$ February 2013.

[26] Control Techniques Ltd.: 'Short Form Guide, Unidrive SP, Part number 0471-0162-02, Issue 2', Emerson Industrial Automation.

[27] Control Techniques Ltd.: 'Installation Guide Unidrive Regen, Part Number 0640-0026-02 Issue 2', Section 7.7, 'Switching frequency emission', Emerson Industrial Automation, 2002.

[28] Draper A.: 'Electrical Machines', Second ed. Chapter 4, 'Windings', Longmans, 1967 p. 69.

[29] Ozelgin I.: 'Analysis of magnetic flux density for airgap eccentricity and bearing faults', International Journal of Systems Applications, Engineering and Development, 2008, 2, pp. 162-169.

[30] Reliance MTR motors: 'Numbers Of Rotor/Stator Slots For 180-440T TEFC Motors', Baldor Electric Company, 2007, online: www.reliance.com/mtr/pcrss.htm, accessed January 2013.

[31] Zappalà, D., Tavner, P.J. and Crabtree, C.J.: 'Gear fault detection automation using WindCon frequency tracking', Proceedings of the EWEA 2012 Wind Energy Annual Event, Copenhagen, Denmark, $16^{\text {th }}-19^{\text {th }}$ April 2012, pp. 1-8.

[32] Caselitz, P., Giebhardt, J., Mevenkamp, M., Reichardt, M.: 'Application of condition monitoring systems in wind energy converters', Proceedings of EWEC97, Dublin, 1997, p. 579-82. 